\title{
مفهوه المثل السائر وخصائصه وما يشابهه من المصطلحات عند العرب MAFHUM AL-MATSAL AS-SA'IR WA KHASHAISHIHI WA MA YUSYABIHUHU MIN AL-MUSHTHALAHAT 'INDA AL-'ARAB
}

\author{
Salih M. Jum'ah Alaso \\ Department of Linguistics, African and European Languages \\ Kwara State University (KWASU), Malete, Nigeria \\ Email:smjalaso@gmail.com
}

تتركز هذه المقالة على تحديد مفهوم الكلمة (المثل) ومشتقاتها المختلفة في المعاجم العربية

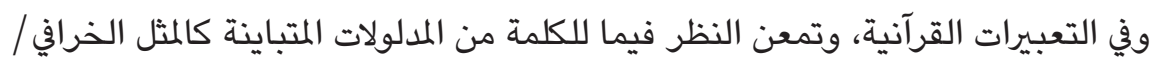

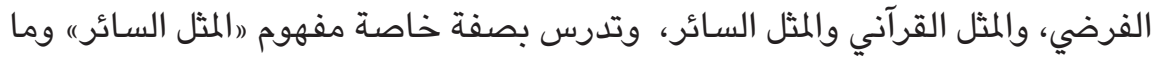

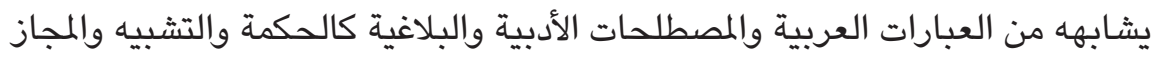

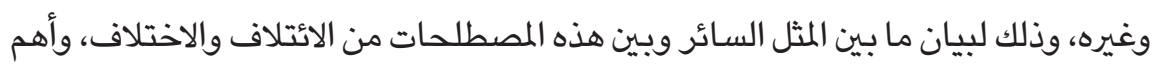

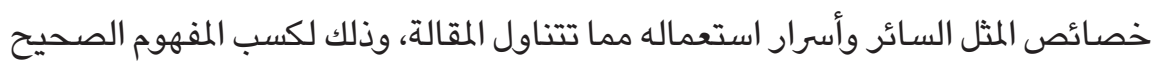

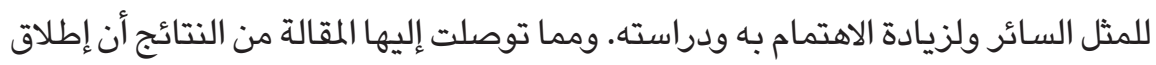

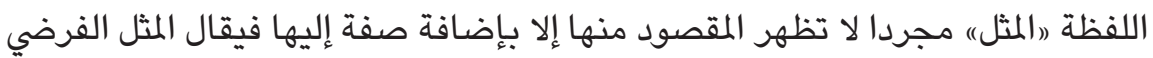

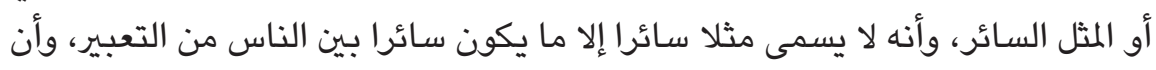

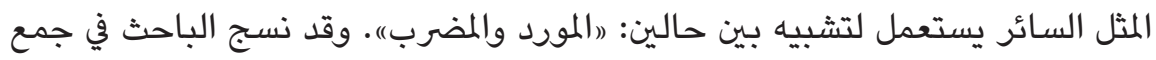
المعلومات وتحليلها على منوال المنهج الوصفي التحليلي كما استعان بالاستبانات المعبئة 
الالكترونية والورقية. وأخيرا اختمت المقالة بعدد من الاقتراحات والتوصيات التي تمت الصلة بفهوم المثل واسستعمالاته.

\section{Abstract}

This paper focuses on explaining the concept of the Arabic word "almatsal" and it's various derivatives in the Arabic lexicology and Qur'anic expressions. It equally explains different usage of the word (Almathal) as Almatha alkhurafi (legendary proverb) almathal alQur'ani (Quranic proverb) etc. The paper particularly concentrates on what is known as "almatsal as-sair" (Common Proverb) and other related literary and rhetoric terms such as idiomatic/ wisdom expression, simile, figure of speech etc, in order to distinguish and make clarification of similarities and dissimilarities among them, characteristics of the said proverb were also discussed. Some of the findings of the paper include: the term "almatsal" has several meanings and usage pending on adjective attached to it, alMathel as-sair can only be used for a common expression and that it is for comparing two different instances (almawrid: where the statement is made for the first time and almadrab: (where the statement is quoted). The researcher followed a descriptive analytical method, and administered both electronic and paper-based questionnaires. The article concluded with a number of suggestions and recommendations.

Keywords: Arab; analytical study; proverb

المثل السائز من فنون الأدب الذي نال أقل الاهتمام لدى الباحثين مما جعل البعض ألها

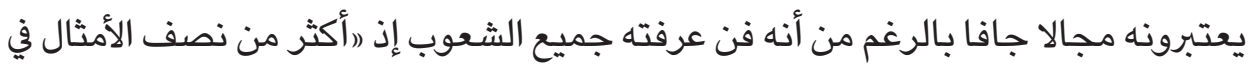

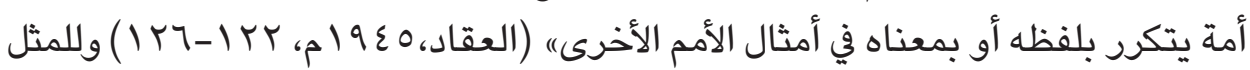

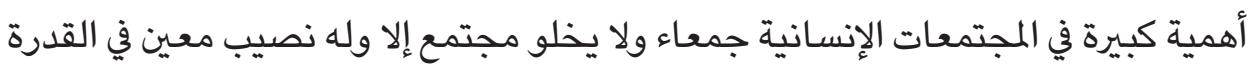

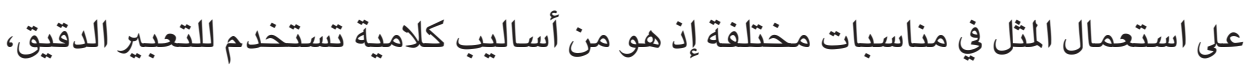

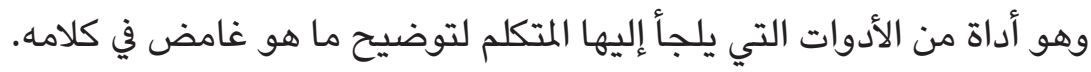

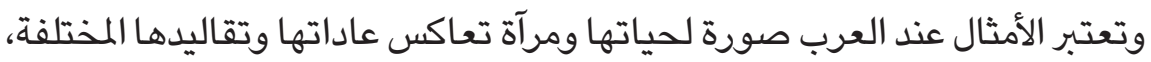

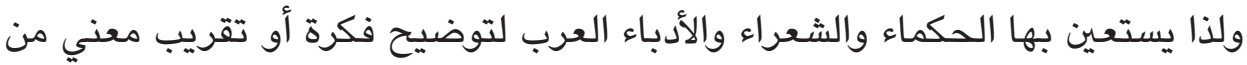

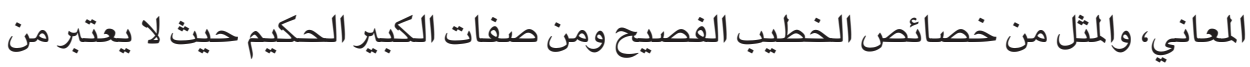

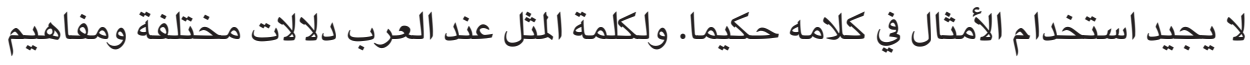

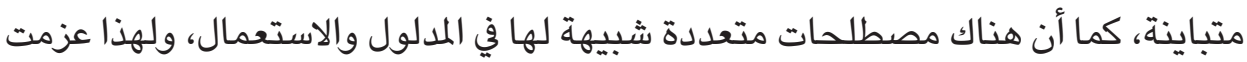


هذه المقالة على تناول بعض هذه المصطلحات وفحص معاني كل واحد ومدلوله وإسناد لكل ما له وإخراج منه ما ليس فيه. وتشتمل المقالة إضافة إلى المقدمة والخاتمة أريعة مباحث: دراسة معجمية واصطلاحية لكلمة (المثل) مدلولات متباينة لكلمة (المثل)"

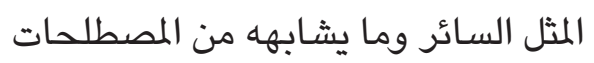
خصائص المثل السائر وأسرار استعماله في الكلام المات

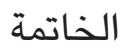

\section{دراسات معجميت واصطلاحيتّل لكلمتّالمثل:}

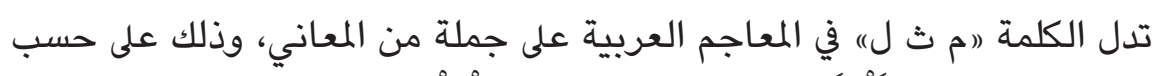

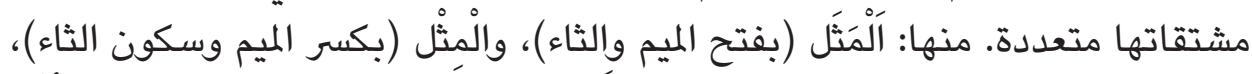

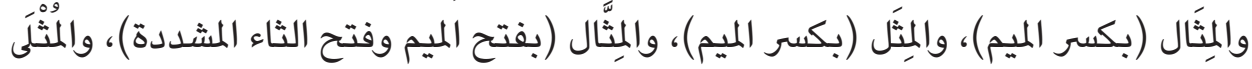

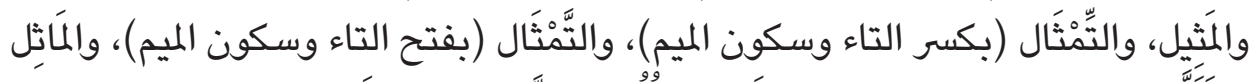

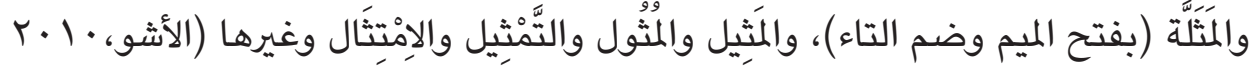

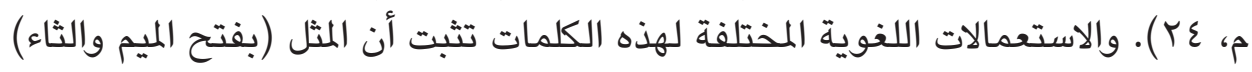

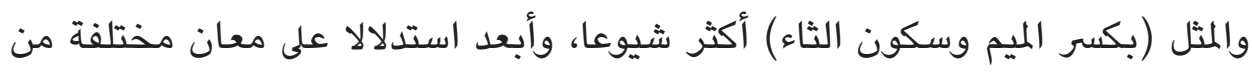

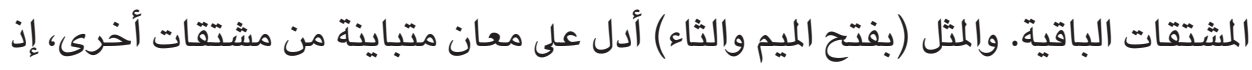
هي تستعمل لتدل على المعاني الآتية:

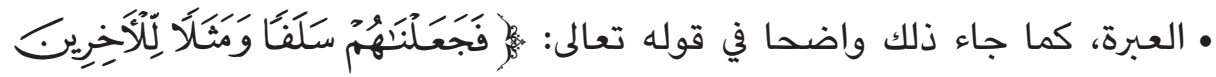
(ابن كثير،

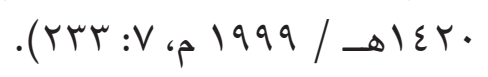

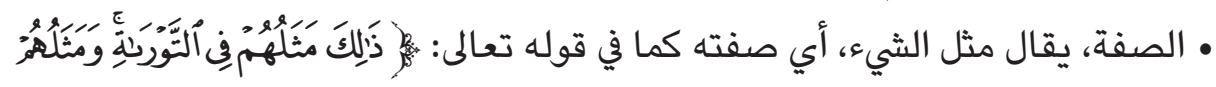

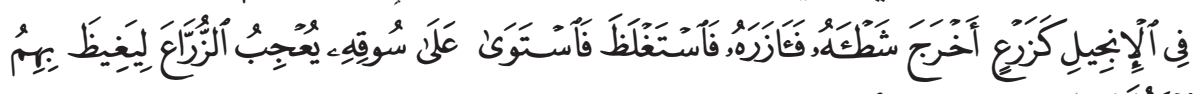

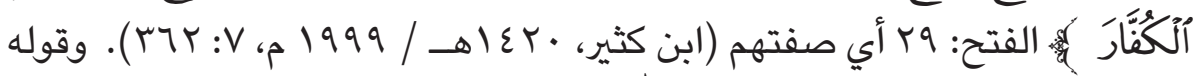
تعالى أيضا:

$$
\text { . }
$$

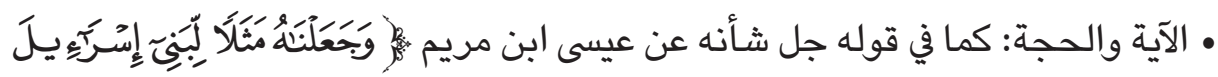


جه

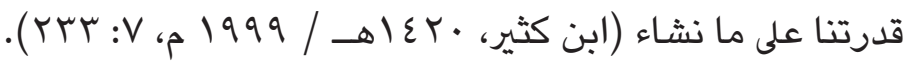

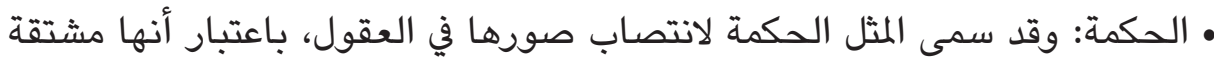

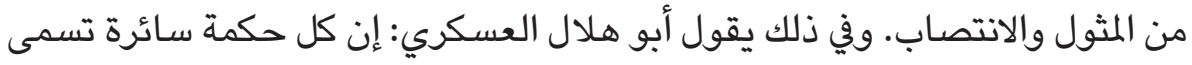

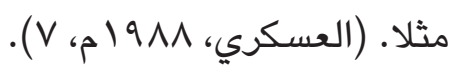

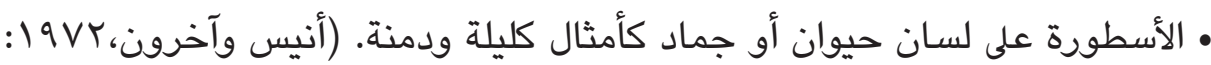

• التسوية: يقال هذا مِثله ومثله كما يقال شبهه وشبهه بمعنى. (ابن منظور، 9 199 :

. (E)rr

ويلاحظ من العرض السابق أن الكلمة (المثل) لغويا تستعمل غالبا لتدل على المشابهة

والمقارنة بين شيئين وهذا هو المعنى الأكثر لها ولكثير من مشتقاتها.

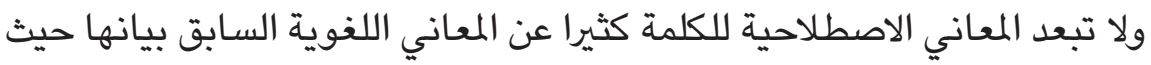

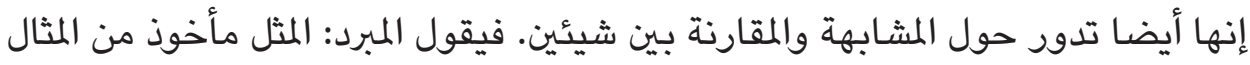

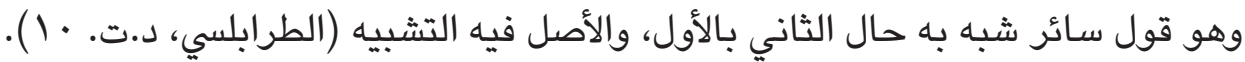

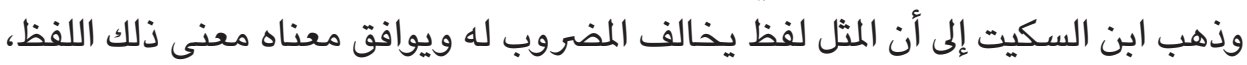

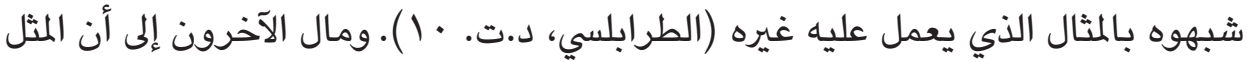

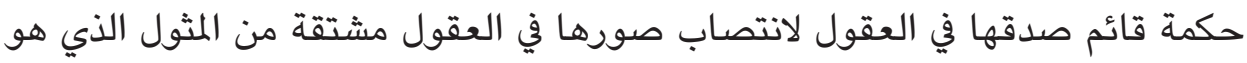

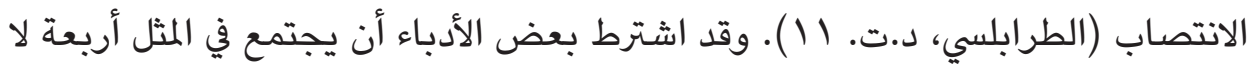

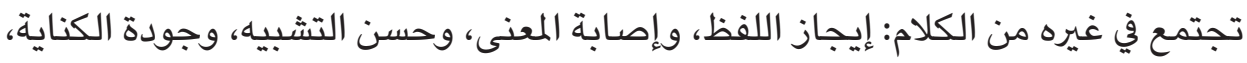

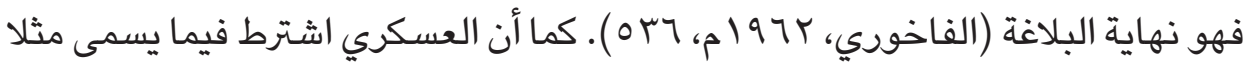

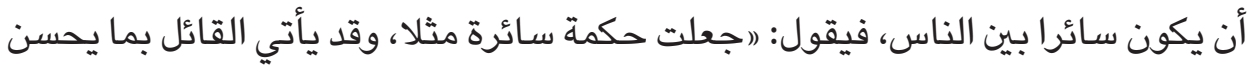

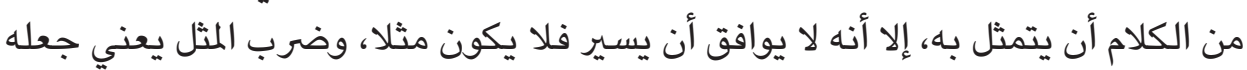

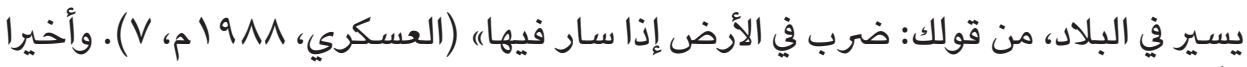

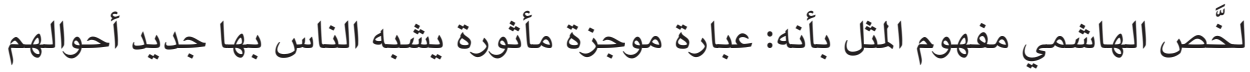

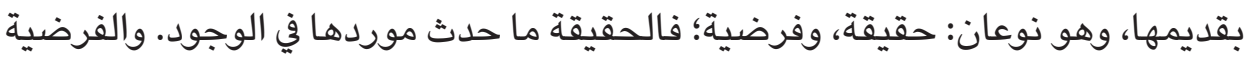

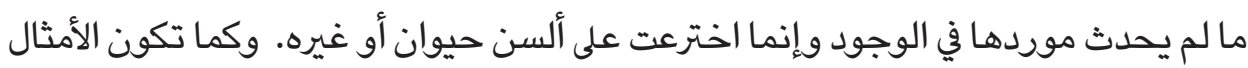

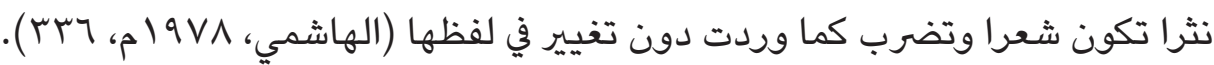




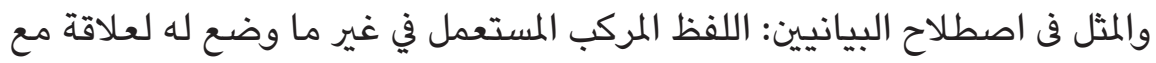

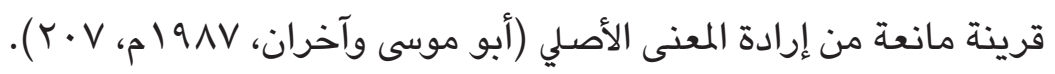

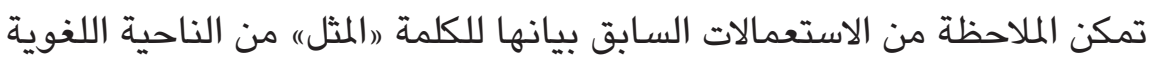

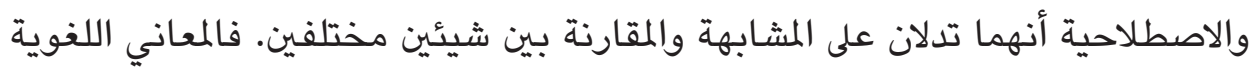
تشير إلى الصفة والعبرة والآية والحجة والحكمة والتصوير والتشبيه وفى هذه المعاني إشارة الشارة إلى أن معنى معينا مشترك بين شيئين مما يؤدى إلى المقارنة والمشابهة والمة ولئه بينهما. مدلولات متباينة لكلمة (المثل)" تستعمل الكلمة (المثل) عند العرب لتدل على ثلاثة أنواع من الكلام وذلك إذا نظرنا

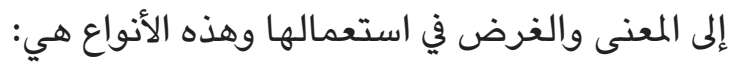

\section{المثل الخرافي أو الفرضي}

وهو عبارة عن تأليف لا حقيقة له في الواقع، وهو في أغلب الأحوال قصة قصيرة،

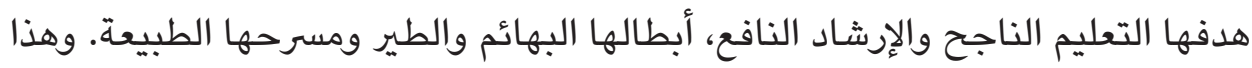

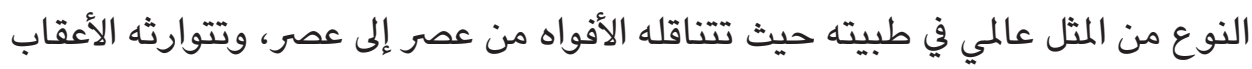

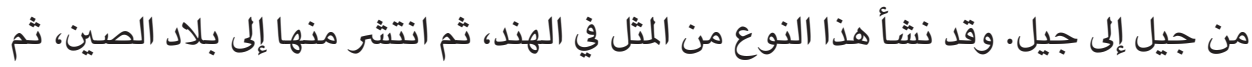

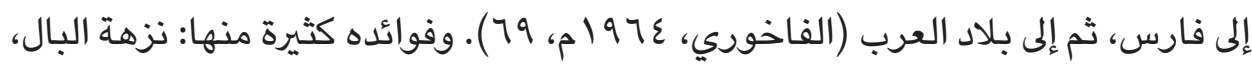

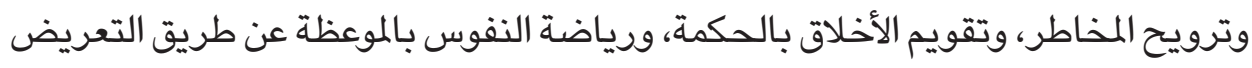

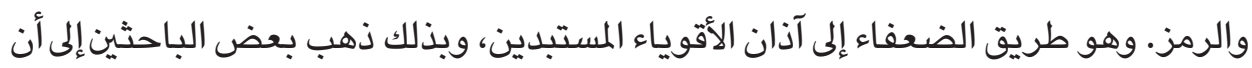

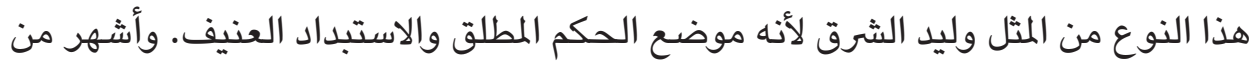

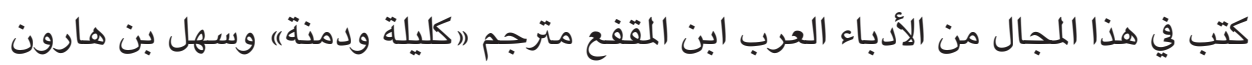

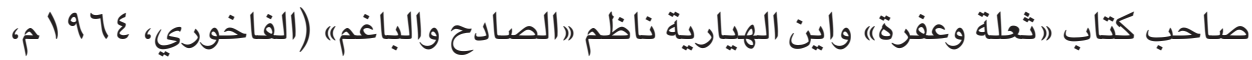

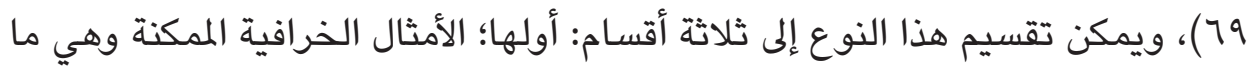

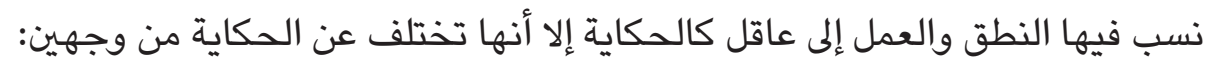

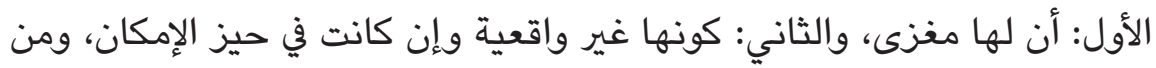

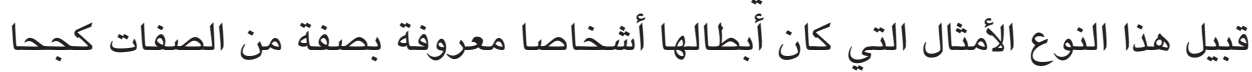

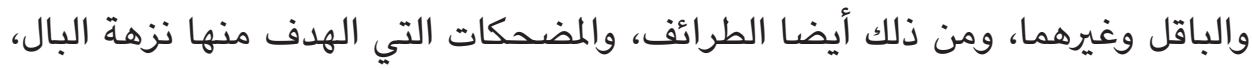

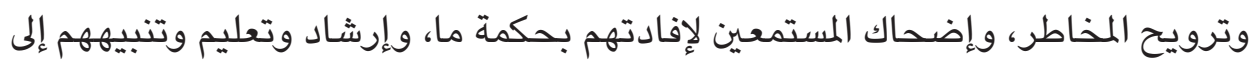
أمر ما عن طريق التلميح والتعريض. 
وثانيها؛ الأمثال الفرضية المستحيلة، وهي ما جاءت على ألسنة الحيوانات والجمادات

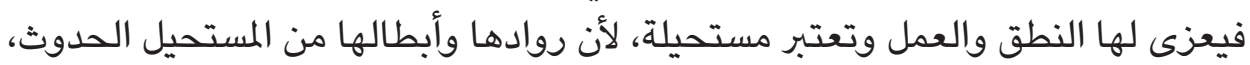

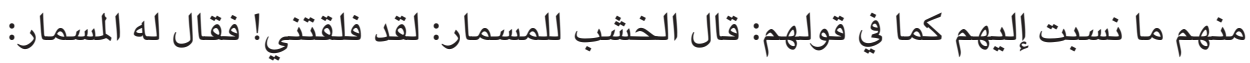

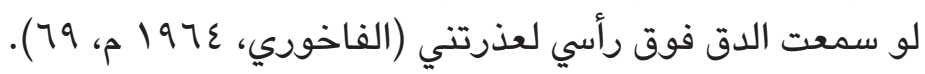

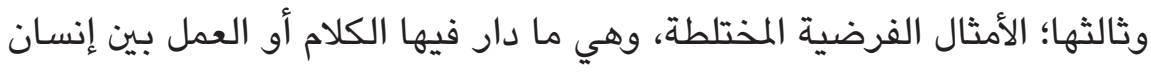

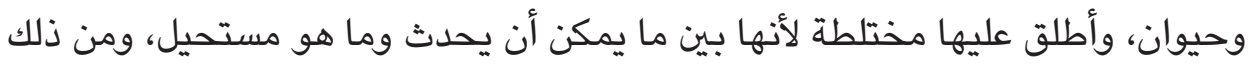

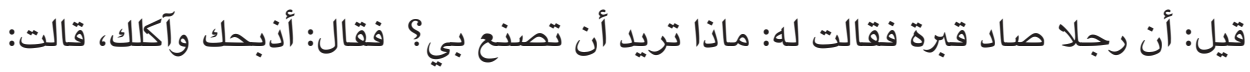

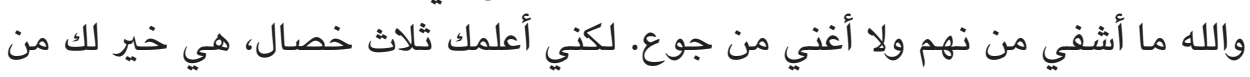

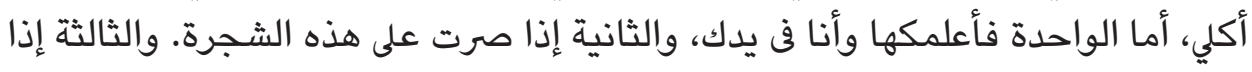

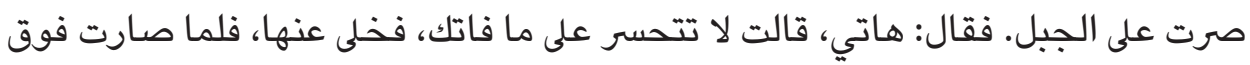

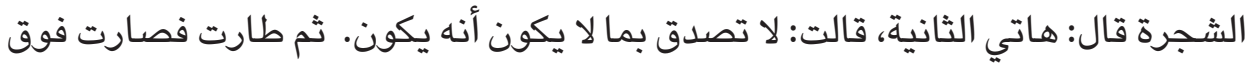
الجبل فقالت: يا شقي لو ذبحتني لأخرجت من حوصلتي جوهرة زنتها عشرون مثقات التالا،

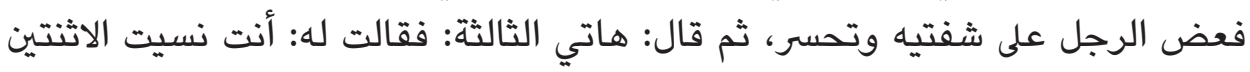

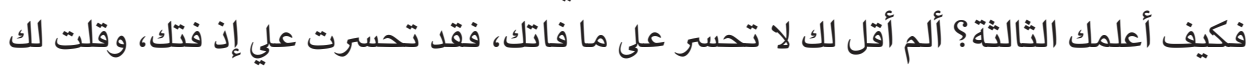

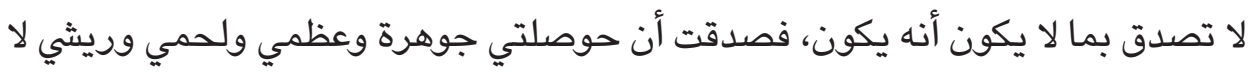

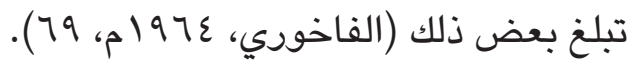

المثل القرآني وهو سرد وصفي أو قصصي، أو صورة بيانية لتوضيح فكرة معينة عن طريق

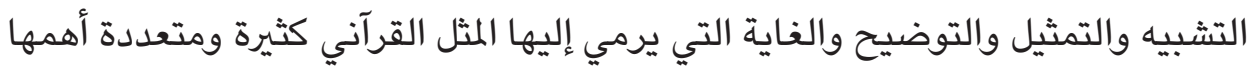

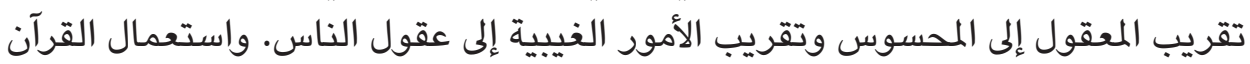

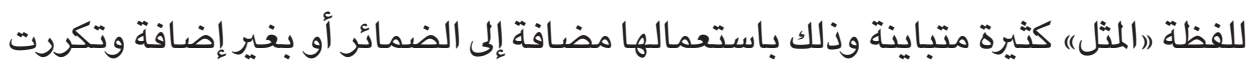

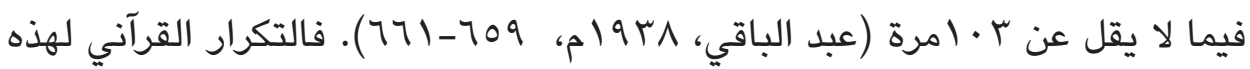

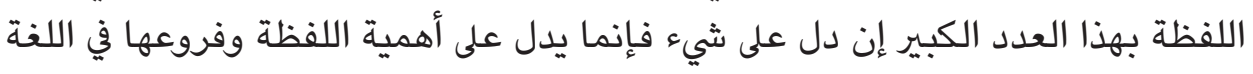

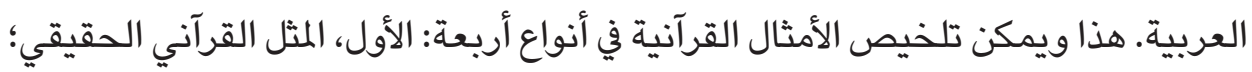

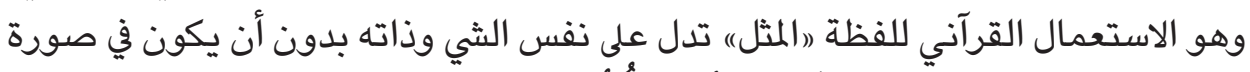

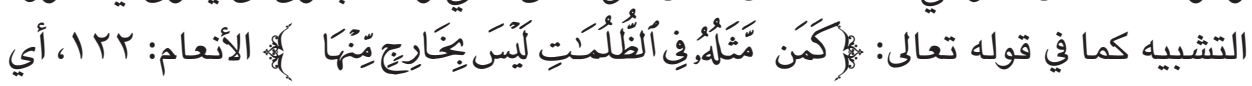

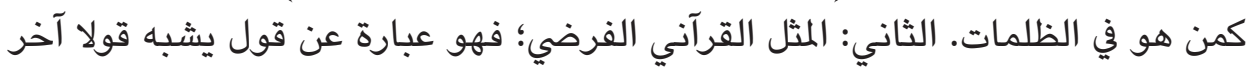

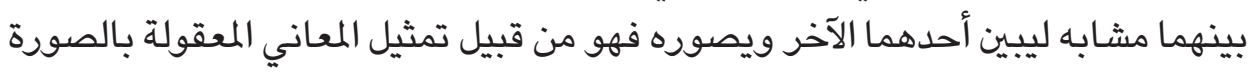


الحسية وعكسه ويأتي على صورة التشبيه ويسمى فرضيا، لأنه وإن كان في حيز الواقع

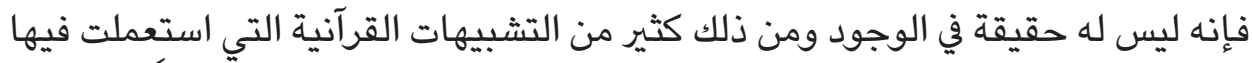

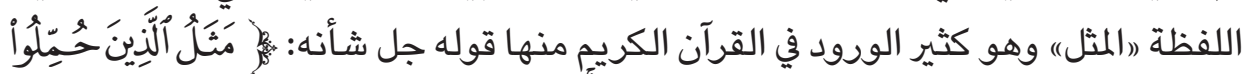

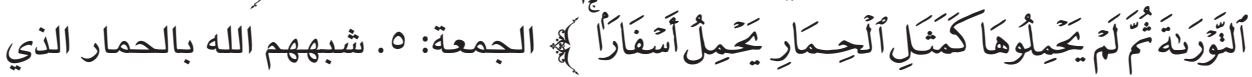

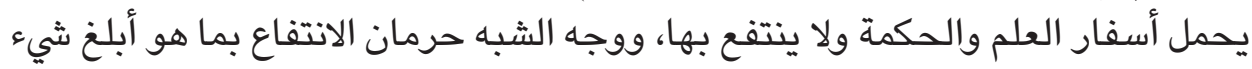

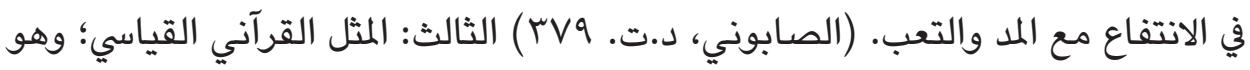

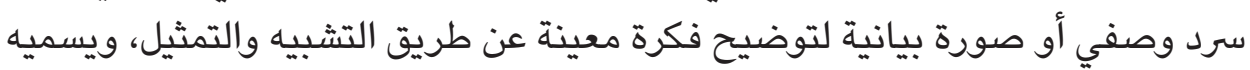

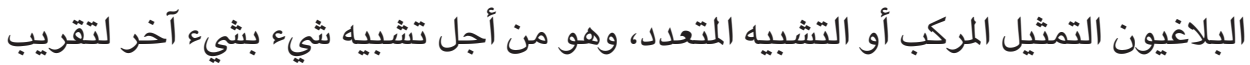

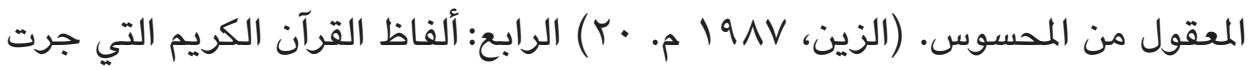

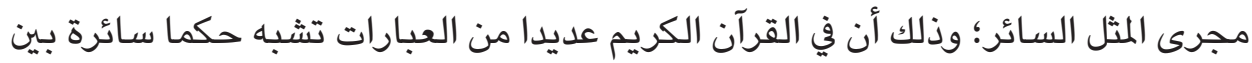

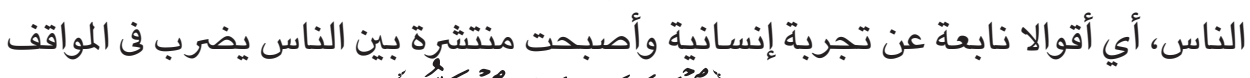

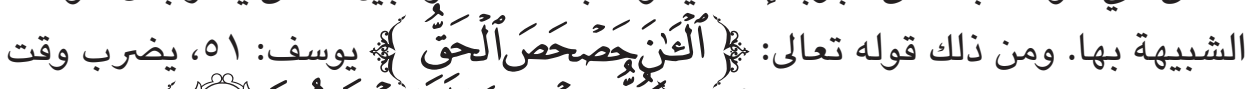

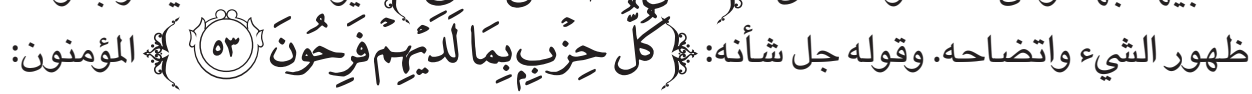

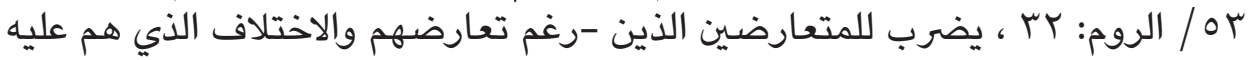

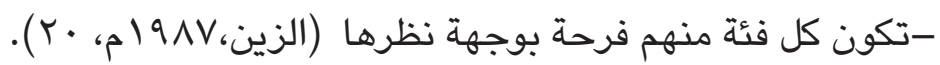

المثل السائر

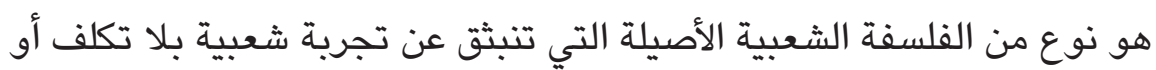

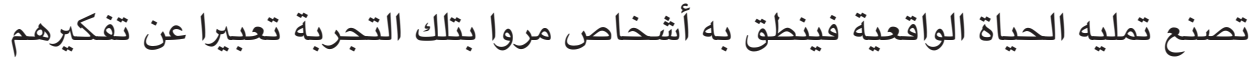

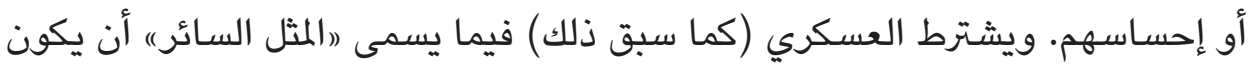

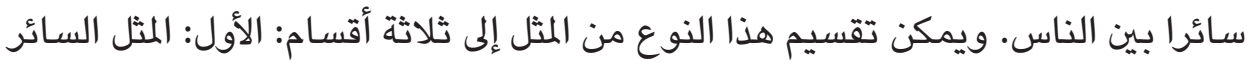

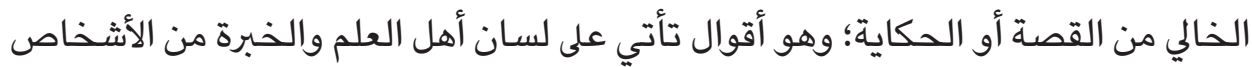

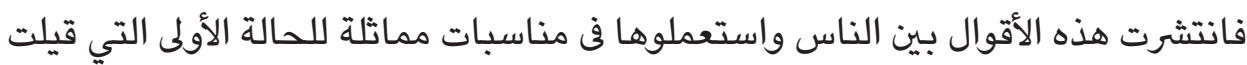

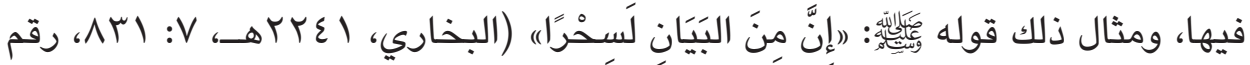

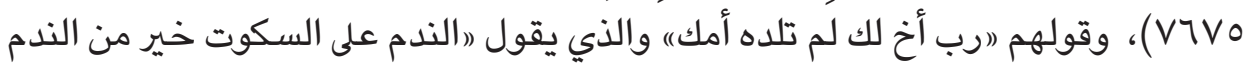

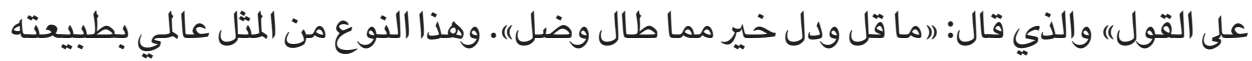
عرفته جميع الأمم بلفظه ويمعناه ، وهذا النوع من المثل هو الذي يشير إليه العقاد بقاد بقوله:

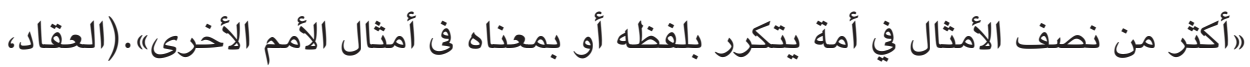

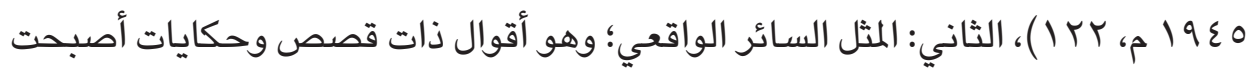


أمثالا عن طريق حادثة حدثت لأشخاص معينين، وقيل المثل أو نقل عنهم أقوال صارت

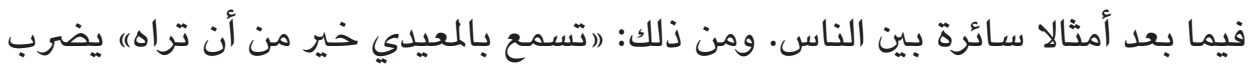

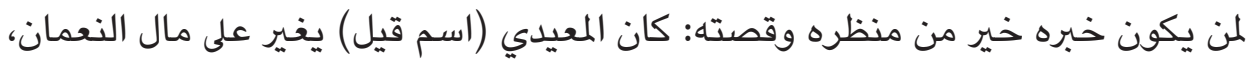

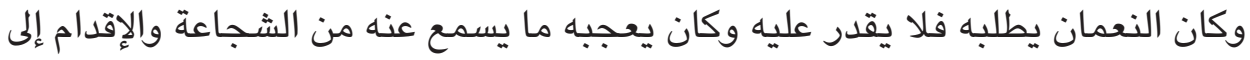

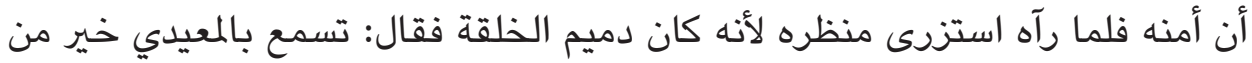

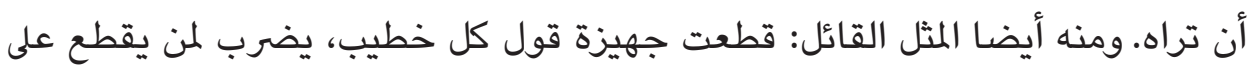

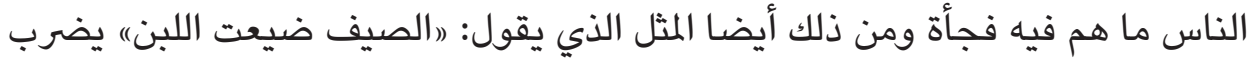

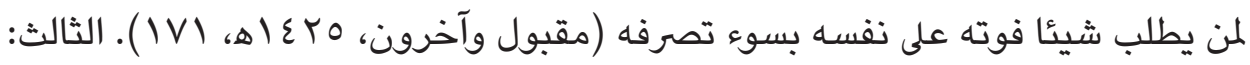

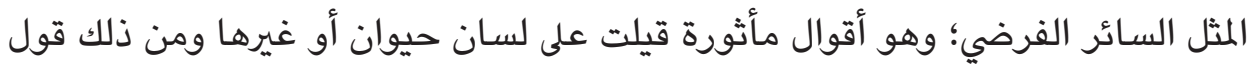

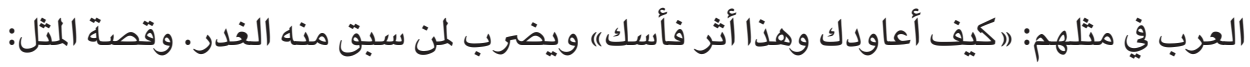
زعموا أن أخوين عاشا بجانب واد خصب فيه حية قاتلة فذهب أحدهما لرعي إبله فقتلته

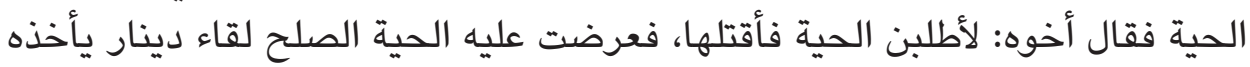

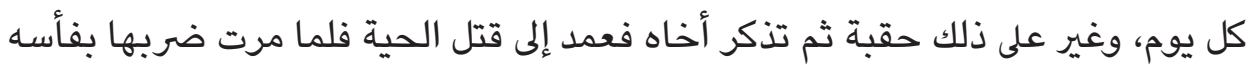

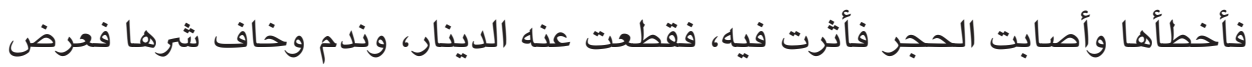

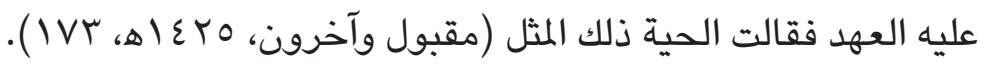

\section{المثل السائر وما يشابهه من المصطلحات عند العرب}

النظر إلى تعريفات المثل السائر السابقة نجد أن هناك اصطلاحات تتضمن تلك ماتك

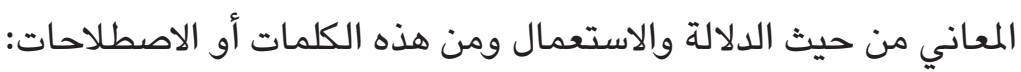

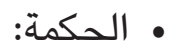

تستعمل الحكمة في كثير من الأحايين مقارنة للمثل، ويقال: الحكم والأمثال، وأنه كثيرا ما يطلق على المثل حكمة ويالعكس ولبيان أوجه الائتلاف والاختلاف بينهما ننظر إليهما بنظرة عميقة.

الحكمة لغة: العلم والتفقه والحلم والعدل والفلسفة والكلام الموافق للحق (أنيس،

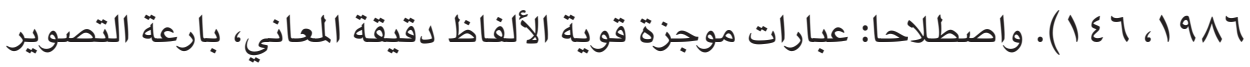

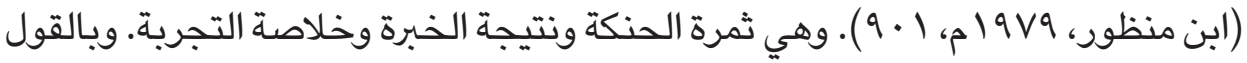
الأخص هي القول الصادر عن تجرية ناجحة، ويمكن النظر إلى الحكمة من ناحيتين:

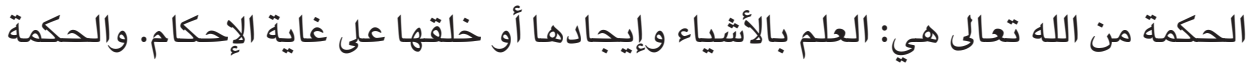

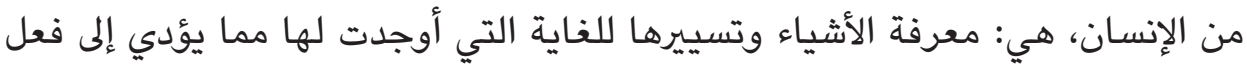




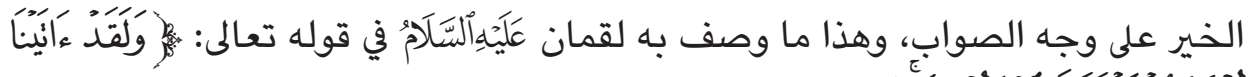

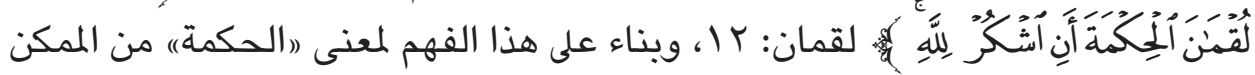

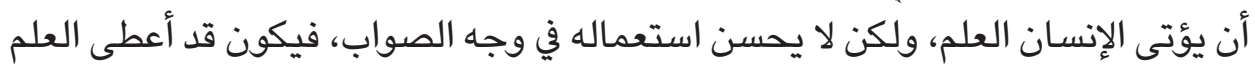

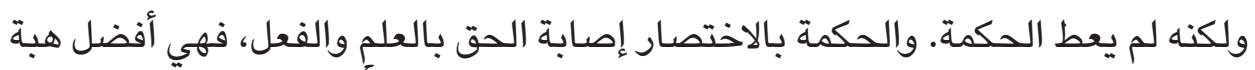

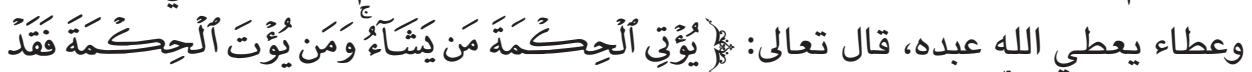

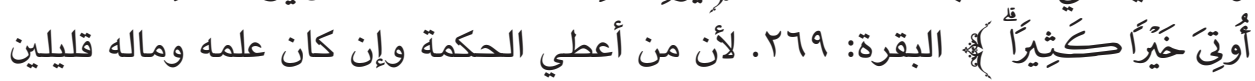

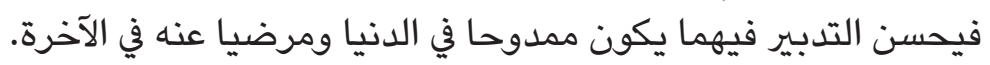

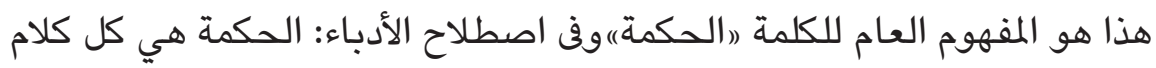

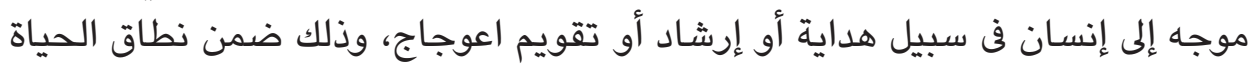

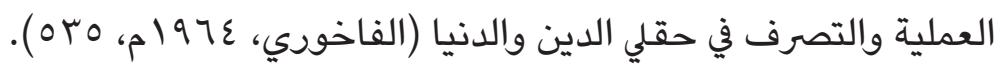

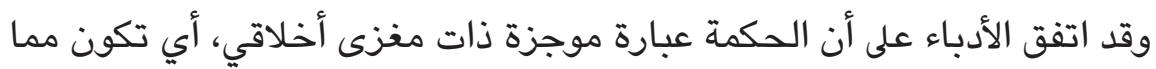

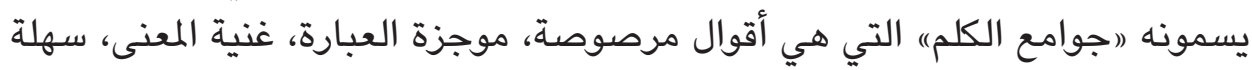

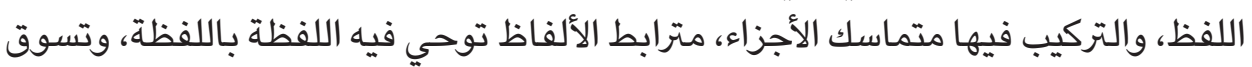

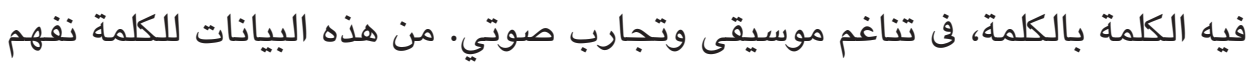

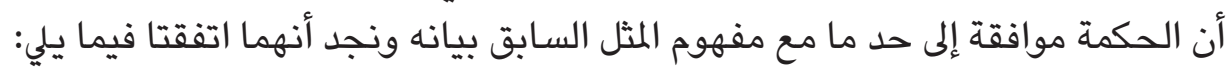
• كل منهما يهدف إلى توجيه الإنسان في حياته من نواحيها المختلفة عن طريق الفيق الفطنة

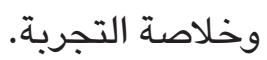
• كل منهما مرصوص العبارة يفيد بألفاظ قليلة معاني كثيرة فيها جمال الصياغة وقوه التأثير.

• كل منهما سهل الحفظ لبلاغة تركيبها وتجاذب ألفاظها وموسيقى تقطيعها.

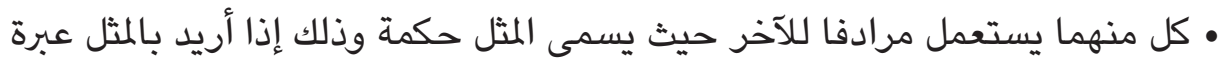

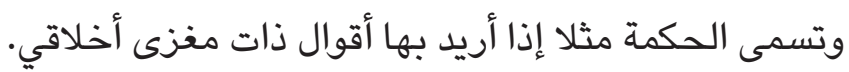
ويالرغم من هذا الاتفاق بينهما إلا أنهما اختلفا فيما يليا لئي: • الحكمة عبارة تجريدية تصيب المعني الصحيح، وتعبر عن تجرية أو خبرة هدفها لإنها

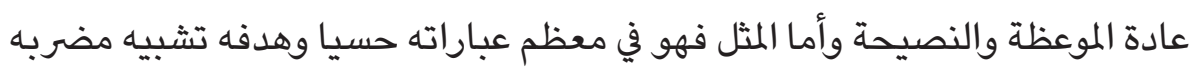
بمورده. • لا يلتزم أن يكون المثل صحيح المنحى فقد اشتهرت أمثال لا يصح معناه فى كل وقت 
ومكان ولكنها صادفت ظرفا شهيرا فانتشرت به. فالمثل القائل: (القتل أنفى للقتل)" ليس صحيح المنحى لأنه ليس كل قتل أنفى للقتل، ومن القتل ما يكون ظلما فيكون

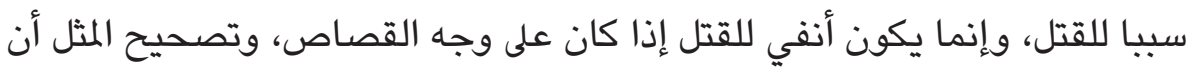
يقال: القتل قصاصا أنفى للقتل ظلما. وأما الحكمة فلابد أن تكون صادئ ولى وجة في جميع الأحوال.

• يجب أن يكون المثل سائرا بين الناس بحيث يكون مشهورا ومعروفا بينهم وذلك إذا

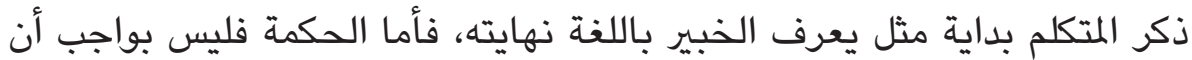

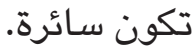
• يجب أن يكون للمثل حالان: حالة المورد (أي الموقع الذي قيل فيه المثل للمرة الأولى)

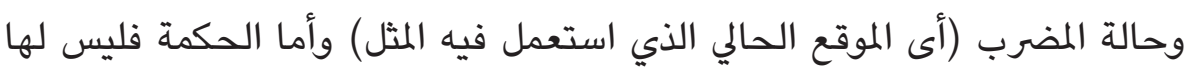
ما يشبه ذلك، وإنما هى تفيد المعنى الذي ترمز إليه ألفاظها. فالحكمة التي تقول:

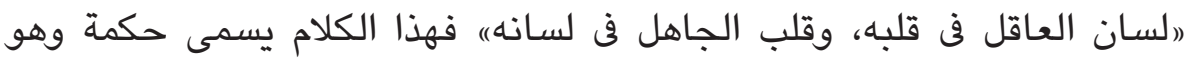
مرصوص العبارة يفيد بأن العاقل من ضبط لسانه والجاهل من لا يحسب كلامه. فالحكمة كهذه تهدف إلى توجيه الحياة عن طريق الفطنة والتجرية السليمة ولا يقف فهمه على معرفة أي مورد كما هو الشأن فى المثل.

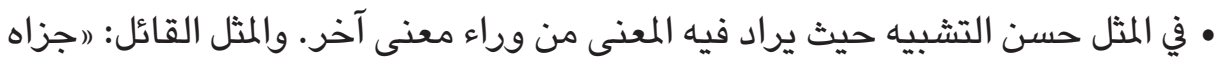
جزاء سنمار) المعنى منه راجع إلى المعنى المستقى من حادث تاريخي حيث جزى منى

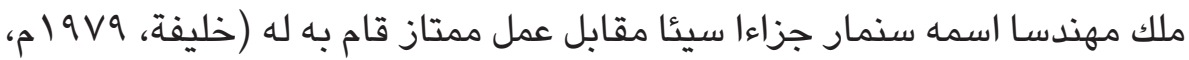

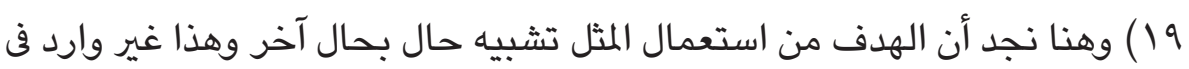

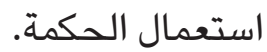

• المثل إنتاج الناس جميعا فهولا يمثل عقليه طبقة معينة وإنما هو يمثل عقلية الأمة

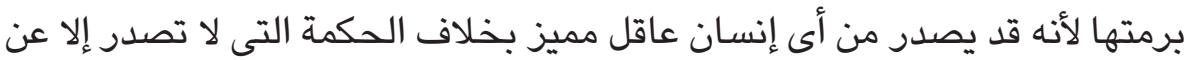
مفكر أو حكيم. فالحكمة وليدة عقل مميز ذي ارتفاع وهي ثمرة الحنكة ونتيجة الخبرة ويذلك تكون صحيحة فى كل مكان وزمان.

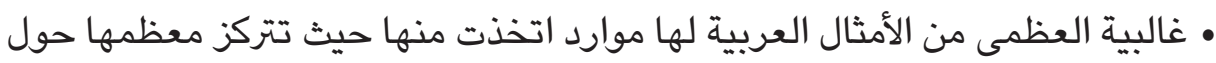
أفراد أو شخصيات أو أشياء عرفت بصفات خاصة كما في أمثال: أبخل من مارد، 
وأجود من حاتم، وأكسى من بصلة، وأما الحكمة فلا تتركز حول هذه الأشياء وإنما هي عبارة ذات مغزى أخلاقي. • كثير من الأمثال لها قصة وحادثة تحكى عنها وتسمى قصة المثل ولا يمكن فهم كثير من الأمثال العربية بدون معرفة هذه القصة وفهمها، فالأمثال: (رقطعت جهيزة قول

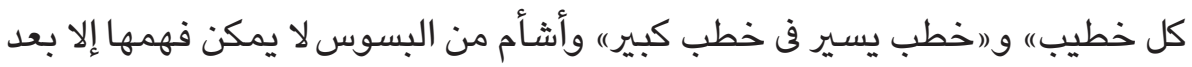
فهم القصة المتعلقة بها، وأما الحكمة في الغالب فليست لها قصة نسبت وليت إليها. • الأمثال تحكى أي أنها تضرب على ما جاءت عن العرب ولا تغير صيغتها فتقول للرجل (الصيف ضيعت اللبن) فتكسر التاء لأنه حكاية.

يستعمل المثل لإظهار التشابه أو ادعائه بين حالين وذلك لتوضيح الصلة بينهما من

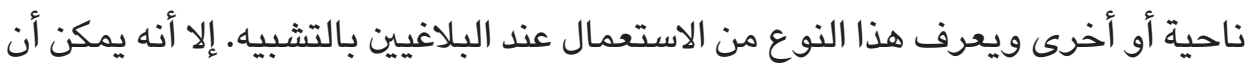

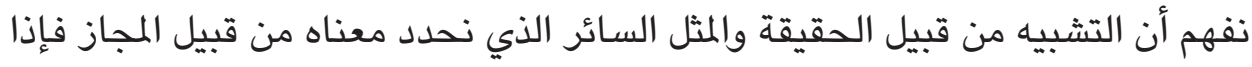

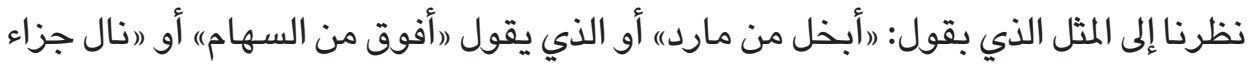
سنمار) في هذه الأمثال مقارنة بين حالين ولكن هذه المقارنة تفهم عن طريق قرينة خارجة ماردية

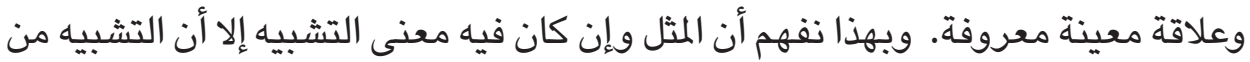
قبيل الكلام الصريح أي الحقيقة والمثل من قبيل الكلام الضمني أو التلميحي أى المجاز.

\section{المجاز}

المجاز في اللغة: من الجواز والتعدية من جاز المكان يجوزه إذا تعداه ثم نقل إلى إنى

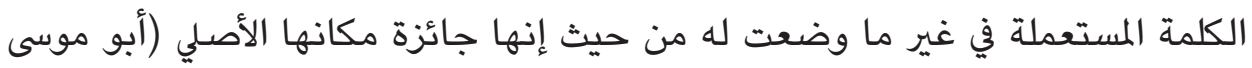

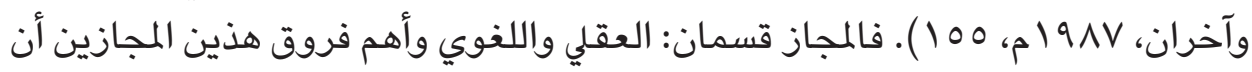

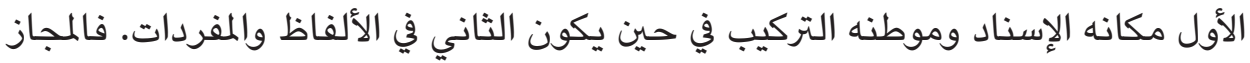

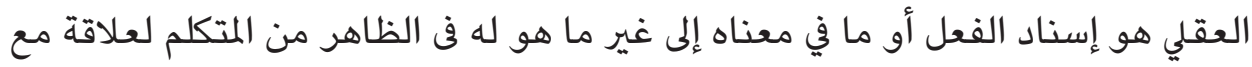

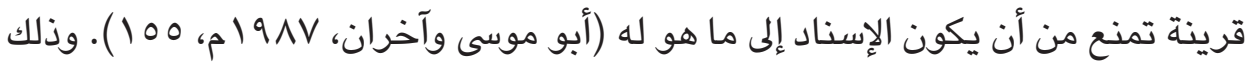

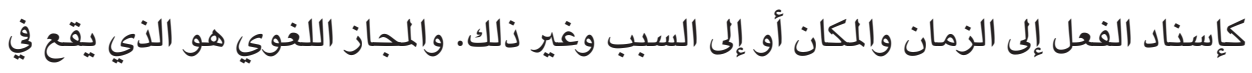

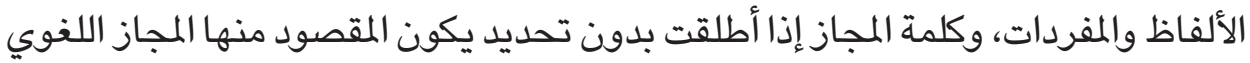
لأنه الأصلي، وهو أربعة أقسام: المجاز المفرد المرسل وهو الكلمة المستعملة في غير معناها 
الأصلي لملاحظة علاقة غير المشابهة مع قرينة دالة على عدم إرادة المعنى الوضعي، وله

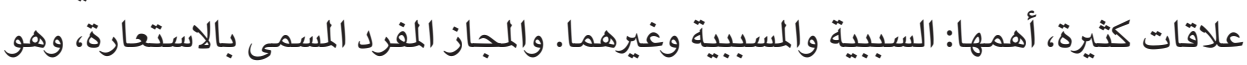

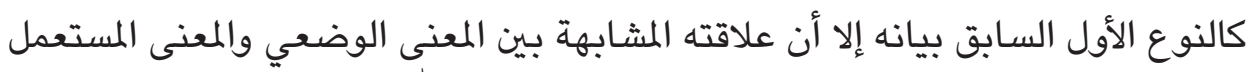

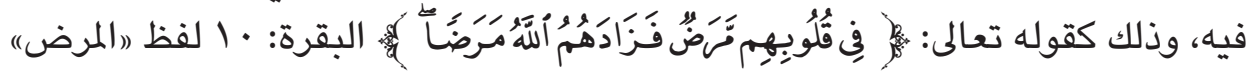

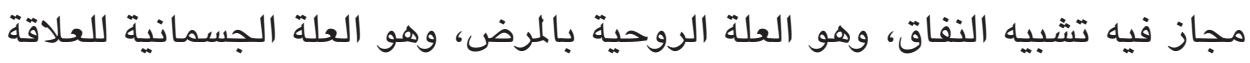

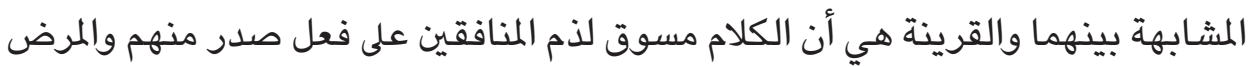
الحقيقي ليس من فعلهم حتى يذموا عليه. (أبو موسى وآخران، 9AV 19 م، 100 1 ) والمجاز

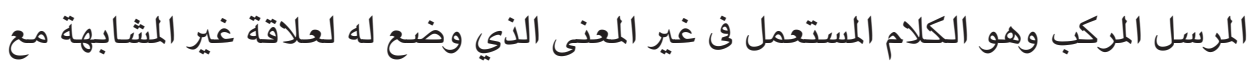

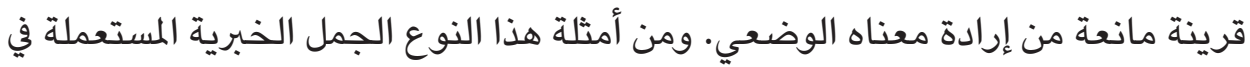

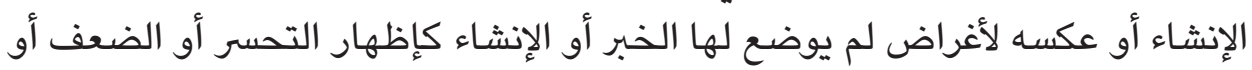

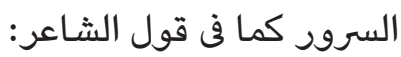

ذهب الصبا وتولت الأيام * فعلى الصبا وعلى الزمان سلام

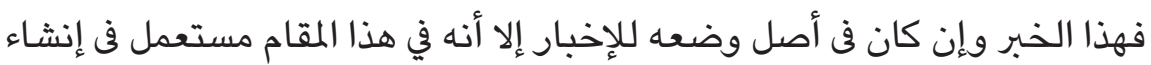
التحسر على ضياع الشباب، وذهاب أيامه. من أنواع المجاز أيضا المجاز المركب المسمى بالاستعارة التمثيلية، وهو تركيب استعمل

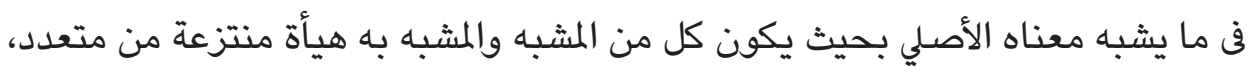

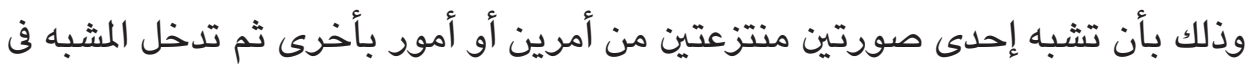

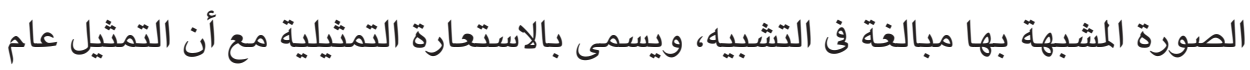
فى كل استعارة للإشارة إلى عظم شانها كأن غيرها ليس فيه تمثيل. وهذه الاستعارة كثيرة

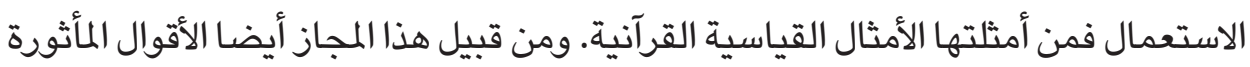

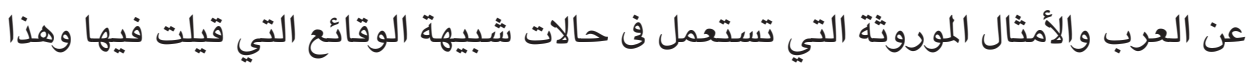

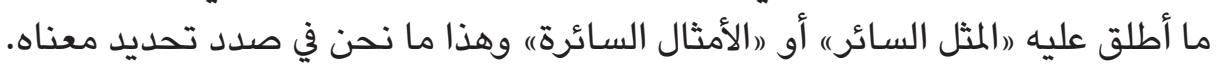

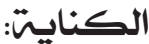

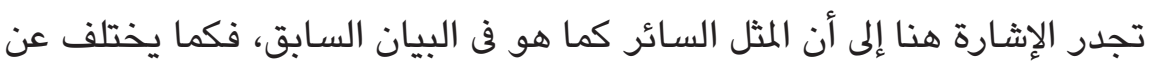

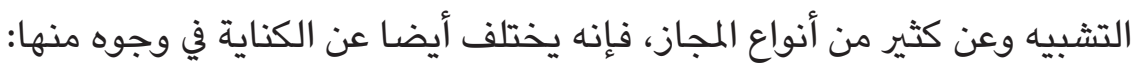

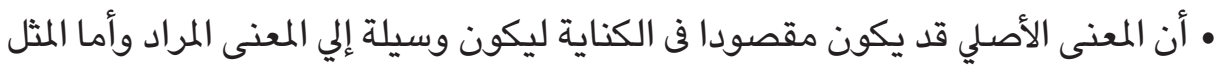
فلا يكون معناه الأصلي مقصودا. • أن العلاقة فى المثل مانعة من إرادة المعني الأصلي حيث يوجد في الكلام ما يثبت أن 
المقصود ليس المورد (الحالة الأولى للمثل) بذاته وإنما المقصود هو إظهار التشابه بين الحالين، وأما الكناية فعلاقتها غير مانعة.

\section{خصائص المثل السائر}

بعد هذه الجودة حول مفهوم المثل السائر وما تميز به عن بقية ما يشابهها من المصطلحات عند العرب بخصائص عديدة نوجزها فيما يلي:

• إيجاز اللفظ: مما يلاحظ في الأمثال السائرة عند العرب أن أغلبيتها العظمى عبلئ عباراتها

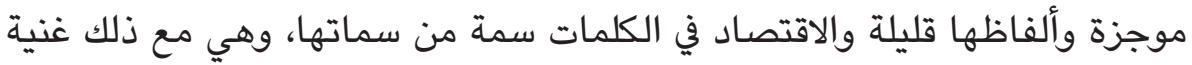

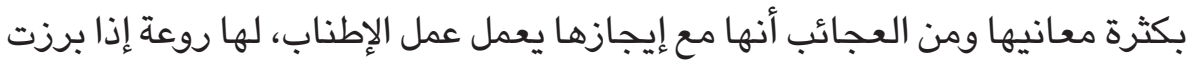

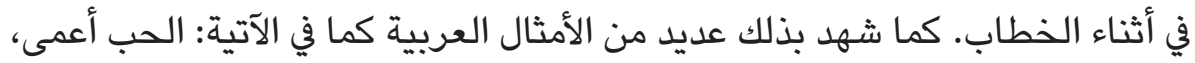
والبعد جفاء، والجار ثم الدار، والجنون فنون، والحرب خدعة، وفي الحركة بركة، ومن هاب خاب. فكل هذه الأمثال مع قلة ألفاظها مملوءة بعدة معان وندان ومحتاج إلى الشرح والبيانات. وهذا شأن كثير من الأمثال العربية السائرة. • إصابة المعنى: تضرب الأمثال لإظهار ما خفير من الماني من المعاني وتقريبها إلى الأذهان،

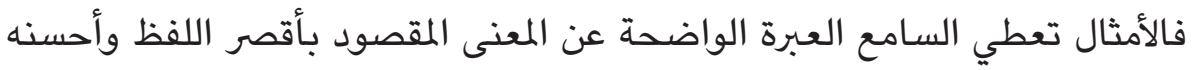

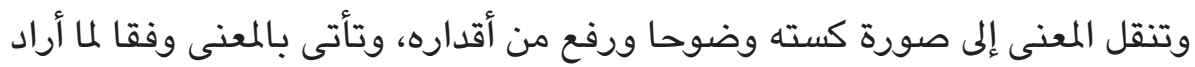
ضارب المثل. فمثلا عندما تواجه شخصا يتحداك بقوته ويحاول أن ينال منك مغترا

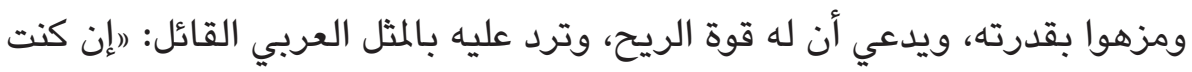

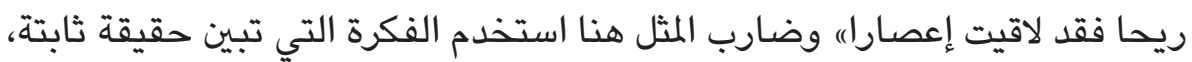
وهي أن الإعصار أقوى من الريح. والمثل هنا قد قرب المعنى المنشود حيث يفهم السامع هذا المعنى مباشرا ويعرف فكرة ضارب المثل وقصده من ضرب المثل. • حسن التشبيه: فالأمثال وإن كان الهدف منها تشبيه حال المورد (الحالة الأولى التي

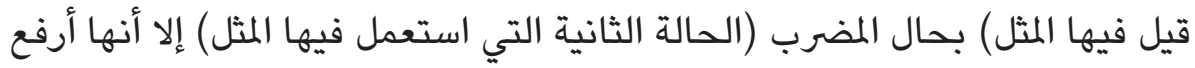
من التشبيه مرتبة، وأحسنه عبارة، وأبلغه مقصدا، وأوجز منه لفظا. فالأمثال الآتية:

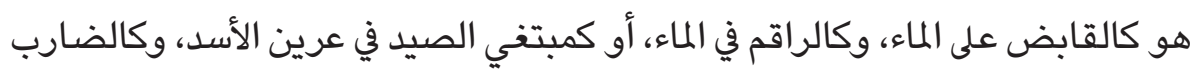
في حديد بارد، كلها أمثال في صيخة التشبيه الصريح تشير معانيها إلى عدم حصول 
المضروب له على فائدة مرجوة فيما يقوم به من الأعمال. وواضح أن هذه العبارات

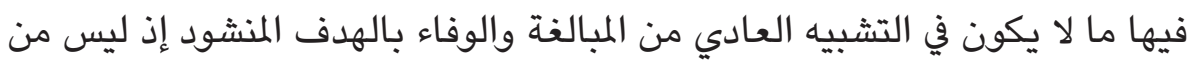

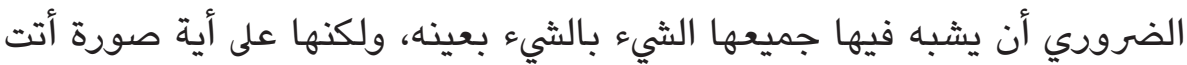

$$
\text { بالمعني المراد وتقربه إلى العقل. }
$$

• جودة الكناية: تستعمل الأمثال للتلميح والإشارة حين لا يريد المتكلم أن يصرح أو إل يشير مباشرة إلى ما يقصده وذلك كما لو حدث لرجل صنع إلى صديقه معروفا فبلالا

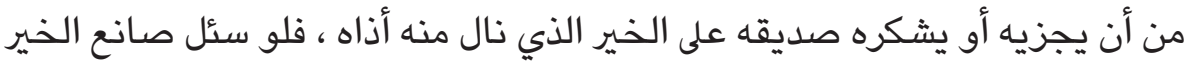

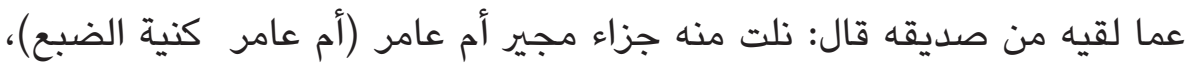
قيل: إن أعرابيا أجارته أم عامر فأجارها وأطعمها فلما صادفت منه منه فرصة أماء أفرسته

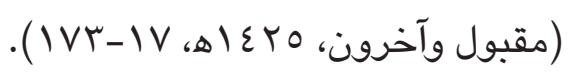

• مرآة لحياة العرب: إن الأمثال صورة لتجارب الهرب لعرب في حياتهم الاجتماعية والسياسية والثقافية والدينية وغيرها. ومن الأمثال التي تصور هذه الحياة المثل الذي يقول:

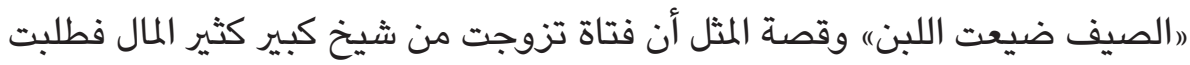

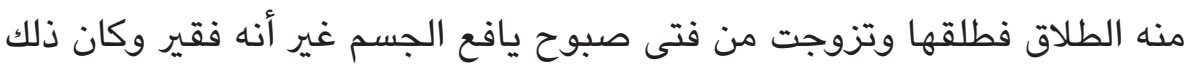
وقت الصيف ولما جاء وقت الشتاء اشتدت بها الحاجة وأرسلت إلى زوجها الأول تطلب منه لبنا فرد عليها بقوله الذي هو المثل السابق (الصيف ضيعت اللبن)، فهذا المثل

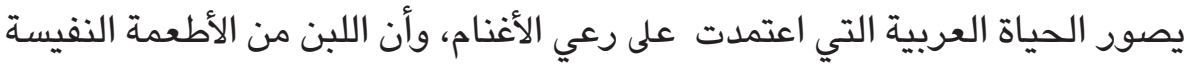

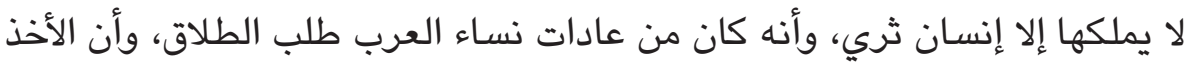
بالثأر وعدم العفو من العادات المشهورة لديهم.

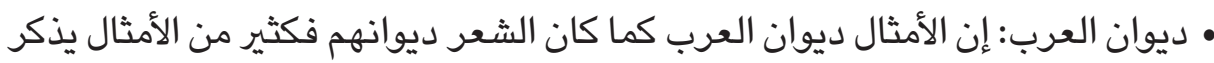

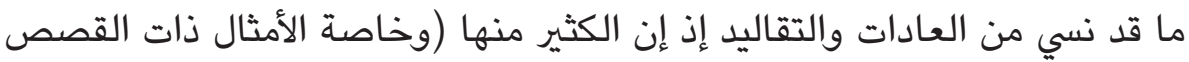

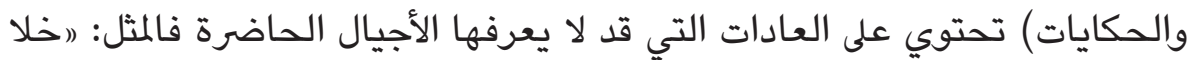
لك الجو فبيضي واصفري" قاله طرفة بن العبد الشاعر الجاهلي المعروف، حيث كان مع عمه في سفر وهو صبي فنزلا على الماء وذهب طرفة يصطاد القنابرة بفخ كان

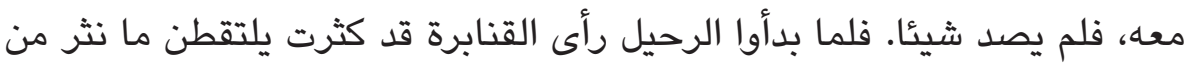

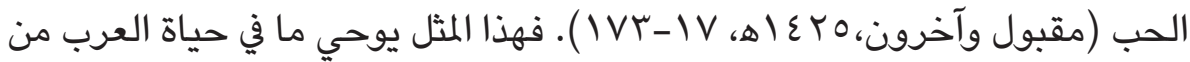




$$
\text { العادات والتقاليد التي قد لا يعرفها الأجيال المعاصرة. }
$$

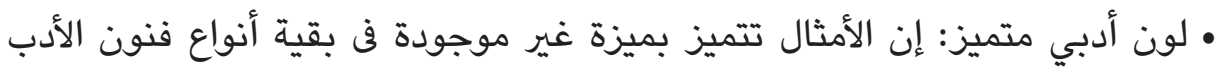
الشفاهي، وهي أنها تبقي على صورة قيل فيها، فالأمثال التي في صيغة التأنيث أو الو

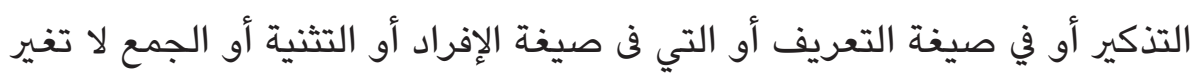
سواء استعملت للإناث أو الذكور أو المفرد أو الجمع وغيرها.

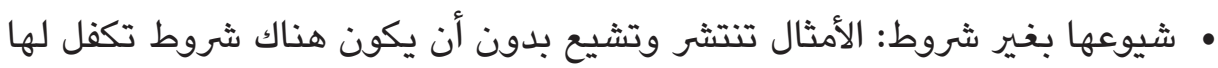

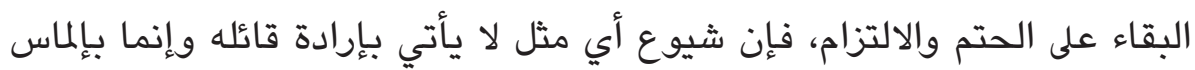
الحاجة إلى تكراره ارتجالا بغير روية ولا اتفاق. فكثير من الأقوال تسقط مع بلاغتها لإنها

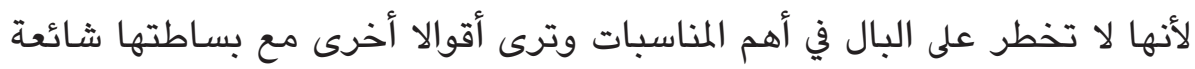
ومشهورة لأنها تلقي تقبلا واستعمالا لدى العامة. • عدم حصرها في طبقة معينة: إن الأمثال لا تمثل عقلية طبقة معينة وإنما هي تمثل عقلية الأمة جميعا، لأنها تصدر من أي إنسان عاقل بخلاف الحكمة التي لا تصدر إلا لإنها

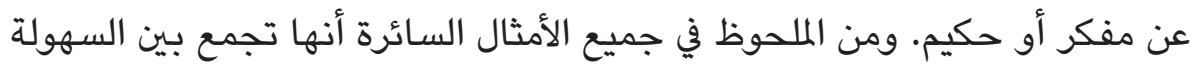

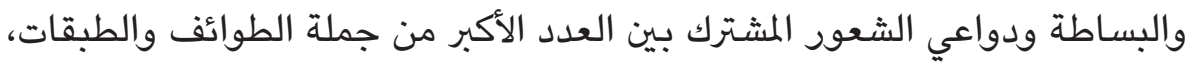

$$
\text { وأن الحكم بالمصادفة فيها أقوى من الحكم المجرب المختبر. }
$$

• للأمثال السائرة العربية رواد وأبطال: كثير من الأمثال العربية يتركز حول أشياء وشخصيات عرفوا بصفات خاصة واتخذهم الناس مضارب الأمثال كما في الأمثال: أبخل من مارد، وأبلغ من قس، وأجود من حاتم، ويعض الأمثال مأخوذة من نبات

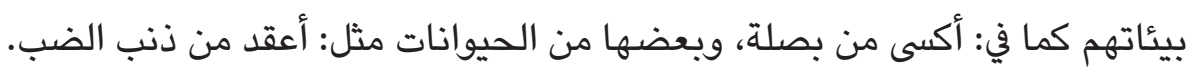
ويعضها الآخر من حياتهم الحربية كقولهم: أفوق من سهم، واعط القوس بأريها. ويعضها نسب القول فيها إلى البهائم تخيلا في قصص أريد بهريه بها نصا نصح وتوجيه كما في

$$
\text { الأمثال الفرضية الخيالية. }
$$

• الأمثال السائرة: المثل قول سائر، يسير من جيل إلى آخر بلفظه ويمعناه، ولذلك يقال لمن جاء بالمثل في كلامه إنه (ضرب المثل) أي جعله يسير في البلاد 


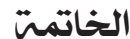

من خلال الجولة السابقة استطاعت المقالة أن تكشف ستار عن مفاهيم مختلفة

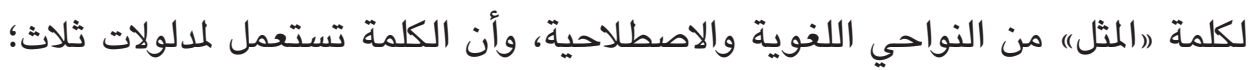

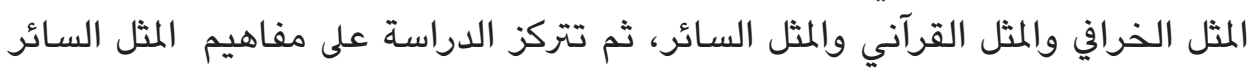

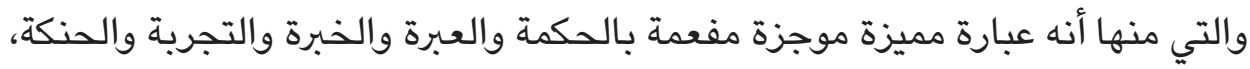

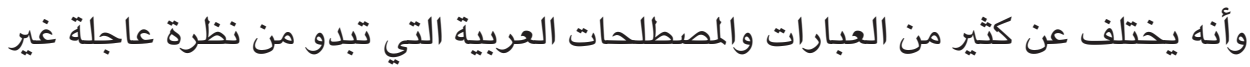

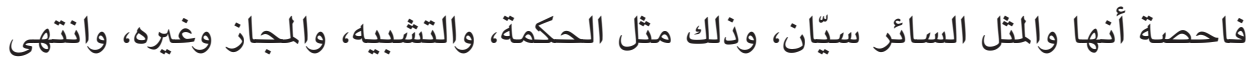

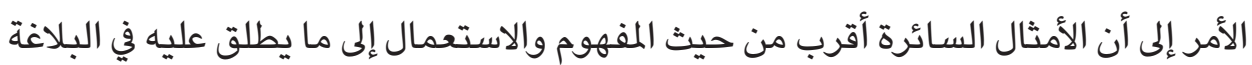

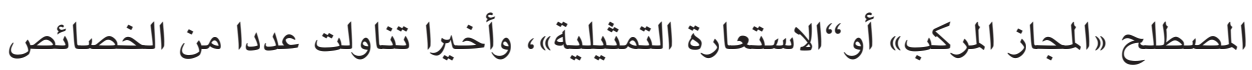

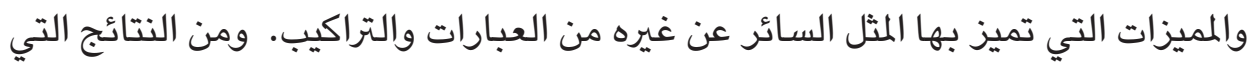

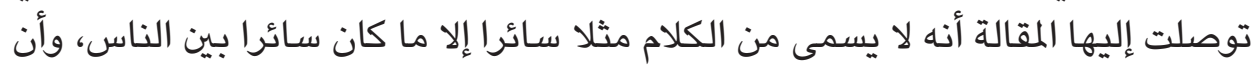

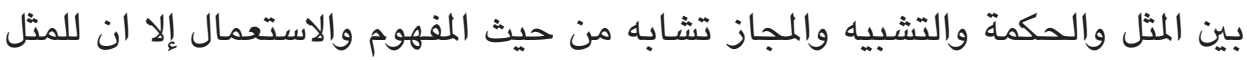

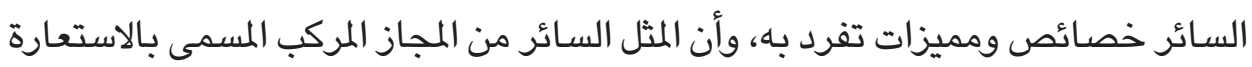

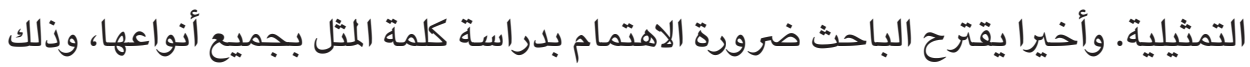

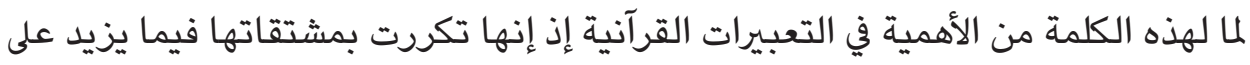
مائة وثلات مرات في الأماكن المختلفة.

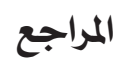

Abu Musa. 1987. 'Ilmu al-Bayan, Dirasah Balaghiyyah Tahliliyyah. Cairo Mesir: Hamadah.

Abd al-Baqi, Muhammad Fuad. 1938. Al-Mu'jam al-Mufahras li al-Fazh al-Qur'an. Beirut Lebanon: Dar al-Fikr.

Alaso, Salih M. Jum'ah. 2010. Dirasat fi al-Amtsal al-Arabiyyah wa al-Yurbuyyah. Ilorin: Mathba'ah Albi.

Anis, Ibrahim wa Akharun. 1972. Al-Mu'jam al-Wasith. Cairo Mesir: Majma‘ al-Lughah al-Arabiyyah.

Anis, Ibrahim. 1986. Al-Munjid fi al-Lughah wa al-I'lam. ath-Thab'ah ats-Tsaminah. Beirut Lebanon: Dar al-Masyriq. 
Al-'Aqqad, Abbas Mahmud. 1945. Ara' fi al-Adab wa al-Funun. Cairo Mesir: al-Hai'ah al-'Ammah li al-Kuttab.

Al-Fakhuri, Hana. 1962. Al-Jadid fi al-Adab al'Arabi wa Tarikhihi. Beirut Lebanon: Dar al-Kitab al-Lubnani.

Al-Fakhuri, Hana. 1964. Al-Insya' al-Jadid. Beirut Lebanon: Mansyurah Maktabah al-Madrasah.

Hasyimi, as-Sayyid al-Marhum Ahmad. 1978. Jawahir al-Adab. Beirut Lebanon: Dar al-Fikr.

Ibnu Katsir, al-Imam Abu al-Fida'. 1992. Tafsir al-Qur'an al-Adhim. Beirut Lebanon: Dar al-Fikr.

Ibnu Mandzur, Abu al-Fadh, Jamaluddin. tahqiq: Abdullah Ali al-Kabir. 1979. Lisan al'Arab. Cairo Mesir: Dar al-Ma'arif.

Khalifah, Muhammad Khalifah. 1979. Al-Adab wa an-Nushush fi al-Ashrain: al-Jahili wa al-Islami. Cairo Mesir: al-Idarah al-'Ammah.lil Ma'ahid alAzhariyyah.

Maqbul, Saad wa akharun. 2005. Al-Adab wa an-Nushush wa al-Balaghah. Libiya: Jam'iyah ad-Da'wah al-Islamiyyah.

Ash-Shabuni, Muhammad Ali. d.t. Shafwah at-Tafasir. Makkah al-Mukarramah - KSA: Jami'ah Umm al-Qura.

Ath-Tharabulasi, Ali Ibrahim al-Hanafi. d.t. Fara'id al-La'ali fi Majma' al-Amtsal Juz 1. (an-Natsr wa mahauhu ghairu madzkurain).

Az-Zain, Sami" 'Athif. 1987. Al-Amtsal wa al-Mits wa at-Tamtsil wa al-Maqalat $f i$ al-Qur'an al-Karim. Beirut Lebanon: asy-Syirkah al-Alamiyyah li al-Kuttab. 
